\title{
Gerakan Pencegahan Stunting Melalui Edukasi pada Masyarakat di Desa Muntoi Kabupaten Bolaang Mongondow
}

\author{
St. Rahmawati Hamzah ${ }^{1}$, Hamzah $B^{2}$ \\ STIKES Graha Medika, \\ Jl. Raya AKD RSI Moonow Lantai II, Mongkonai Barat, Kotamobagu ${ }^{1,2}$ \\ Email: rahmahamzah94@gmail.com ${ }^{1}$
}

\begin{abstract}
ABSTRAK
Kasus stunting di Indonesia masih tergolong tinggi dengan menyentuh angka 30,8\%. Angka ini masih jauh dari standar WHO yaitu 20\%. Angka prevalensi stunting di Sulawesi Utara sebesar 25,5\%, meskipun angka stunting Sulawesi Utara di bawah angka nasional $(30,8 \%)$ namun masih ada empat daerah dengan angka prevalensi stunting yang cukup tinggi termasuk kabupaten Bolaang Mongondow sebesar 30,6\%. Tujuan pengabdian ini adalah untuk meningkatkan pengetahuan masyarakat Desa Muntoi Kecamatan Passi Barat Kabupaten Bolaang Mongondow tentang pencegahan stunting. Metode yang digunakan adalah ceramah interaktif dan tanya jawab. Hasil penyuluhan menunjukkan bahwa rata-rata skor pengetahuan masyarakat tentang stunting pada saat pre-test adalah 10,43 dan pada saat post-test meningkat menjadi 19,60. Dampak pengabdian ini adalah meningkatnya pengetahuan masyarakat tentang pencegahan stunting dengan perbedaan nilai rata-rata skor pengetahuan peserta penyuluhan pada saat pre-test dan post-test dengan angka 9,17. Untuk itu disarankan kepada masyarakat khususnya pada ibu untuk melakukan pencegahan stunting dengan pemenuhan asupan gizi selama hamil, melahirkan dan anak sebelum usia 2 tahun.
\end{abstract}

Kata kunci: Edukasi; Pencegahan; Stunting

\begin{abstract}
Stunting cases in Indonesia are still high, touching 30.8\%. This figure is still far from the WHO standard of 20\%. The stunting prevalence rate in North Sulawesi is $25.5 \%$, although North Sulawesi's stunting rate is below the national rate $(30.8 \%)$, there are still four regions with a fairly high stunting prevalence rate including Bolaang Mongondow district of 30.6\%. The purpose of this service is to increase the knowledge of the people of Muntoi Village, Passi Barat District, Bolaang Mongondow Regency about the prevention of stunting. The methods used are interactive lectures and question and answer. The results showed that the average score of public knowledge about stunting at the pre-test was 10.43 and at the time of the post-test it increased to 19.60. The impact of this service is an increase in public knowledge about stunting prevention with the difference in the mean score of knowledge of the extension participants during the pre-test and posttest with a figure of 9.17. For this reason, it is recommended to the public, especially mothers, to prevent stunting by fulfilling nutritional intake during pregnancy, childbirth and children before the age of 2 years.
\end{abstract}

Keywords: Education; Prevention; Stunting

\section{PENDAHULUAN}

Stunting masih menjadi masalah kesehatan masyarakat di negara berkembang seperti Indonesia dengan prevalensi yang cukup tinggi. Stunting disebabkan oleh kekurangan 
asupan gizi dalam waktu lama pada masa 1000 hari pertama kehidupan (HPK) yang merupakan masa-masa pemenuhan gizi untuk balita. Standar baku WHO-MGRS (Multicentre Growth Reference Study) tahun 2005 menunjukkan, nilai z-scorenya kurang dari -2SD dikatagorikan pendek, dan dikategorikan sangat pendek jika nilai z-scorenya kurang dari -3SD (Kemenkes RI, 2016).

Data Riset Kesehatan Dasar (Kemenkes RI, 2018) menunjukkan kasus stunting di Indonesia masih tergolong tinggi dengan menyentuh angka 30,8\% yang terdiri dari $11,5 \%$ sangat pendek dan 19,3\% pendek. Data lebih lanjut menunjukkan angka prevalensi stunting di Sulawesi Utara sebesar 25,5\%, meskipun angka stunting Sulawesi Utara di bawah angka nasional $(30,8 \%)$ namun angka ini masih belum aman karena masih belum mencapai angka stunting yang direkomendakikan oleh WHO sebesar 20\%. Berdasarkan data Dinkes Sulut 2018 daerah yang diatas capaian provinsi Sulawesi Utara, adalah Kabupaten Kepulauan Sangihe (35\%), Bolaang Mangondow Timur (32,4\%), Bolaang Mangondow (30,6\%), dan Kota Manado (28\%) (Dinkes Sulut, 2019).

Hasil penelitian sebelumnya menemukan bahwa prevalensi stunting di Indonesia termasuk di Kabupaten Bolaang Mongondow masih cukup tinggi adalah pola asuh orangtua yang kebiasaan pemberian makan, kebiasaan pengasuhan, kebiasaan kebersihan dan kebiasaan mendapatkan pelayanan kesehatan yang masih kurang (Bella et al., 2020). Penelitian lain yang dilakukan oleh (Rahmayana, 2014) menemukan bahwa selain pola asuh orang tua faktor sanitasi lingkungan dan rangsangan psikososial juga berhubungan dengan kejadian stunting pada anak usia 24-59 bulan. Anak yang terkena stunting dapat terhambat perkembangan otaknya. Setelah dewasa, kecerdasan dan performa edukasinya menjadi tidak optimal, di samping bisa juga terkena risiko penyakit metabolik (Yadika et al., 2019).

Upaya dalam pencegahan stunting adalah perubahan perilaku masyarakat melalui program promosi kesehatan dan pemberdayaan masyarakat yang semuanya berupaya untuk melakukan intervensi dalam perubahan perilaku positif terkait dengan pengetahuan ibu tentang asupan gizi selama hamil, melahirkan dan anak sebelum usia 2 tahun.

Studi pendahuluan yang dilakukan di Desa Muntoi Kecamatan Passi Barat Kabupaten Bolaang Mongodow menunjukkan bahwa pengetahuan masyarakat tentang pencegahan stunting masih kurang. Data yang diperoleh hanya 34\% masyarakat yang mengetahuai tentang pencegahan stunting melalui pemenuhan asupan gizi. Hasil wawancara menyebutkan, masyarakat kurang melakukan pemenuhan gizi selain masalah pengetahuan yang kurang juga disebabkan oleh masalah ekonomi keluarga. 
Berdasarkan permasalahan di atas, kami tim dosen STIKES Graha Medika melakukan pengabdian pada masyarakat bertujuan untuk meningkatkan pengetahuan masyarakat tentang pencegahan stunting melalui promosi kesehatan sebagai edukasi kepada masyarakat.

\section{METODE}

Pengabdian masyarakat ini dilaksanakan di Desa Muntoi. Sasaran pelaksanaan pengabdian adalah masyarakat dusun 03 Desa Muntoi Kecamatan Passi Barat Kabupaten Bolaang Mongondow. Waktu pelaksanaan pengabdian ini tanggal 2 dan 3 Desember 2019. Kegiatan yang dilakukan meliputi tiga tahap yaitu tahap perencanaan, tahap pelaksanaan, dan tahap evaluasi. Adapun tahapan pelaksanaannya pengabdian ini seperti yang ditunjukkan dalam gambar 1 .

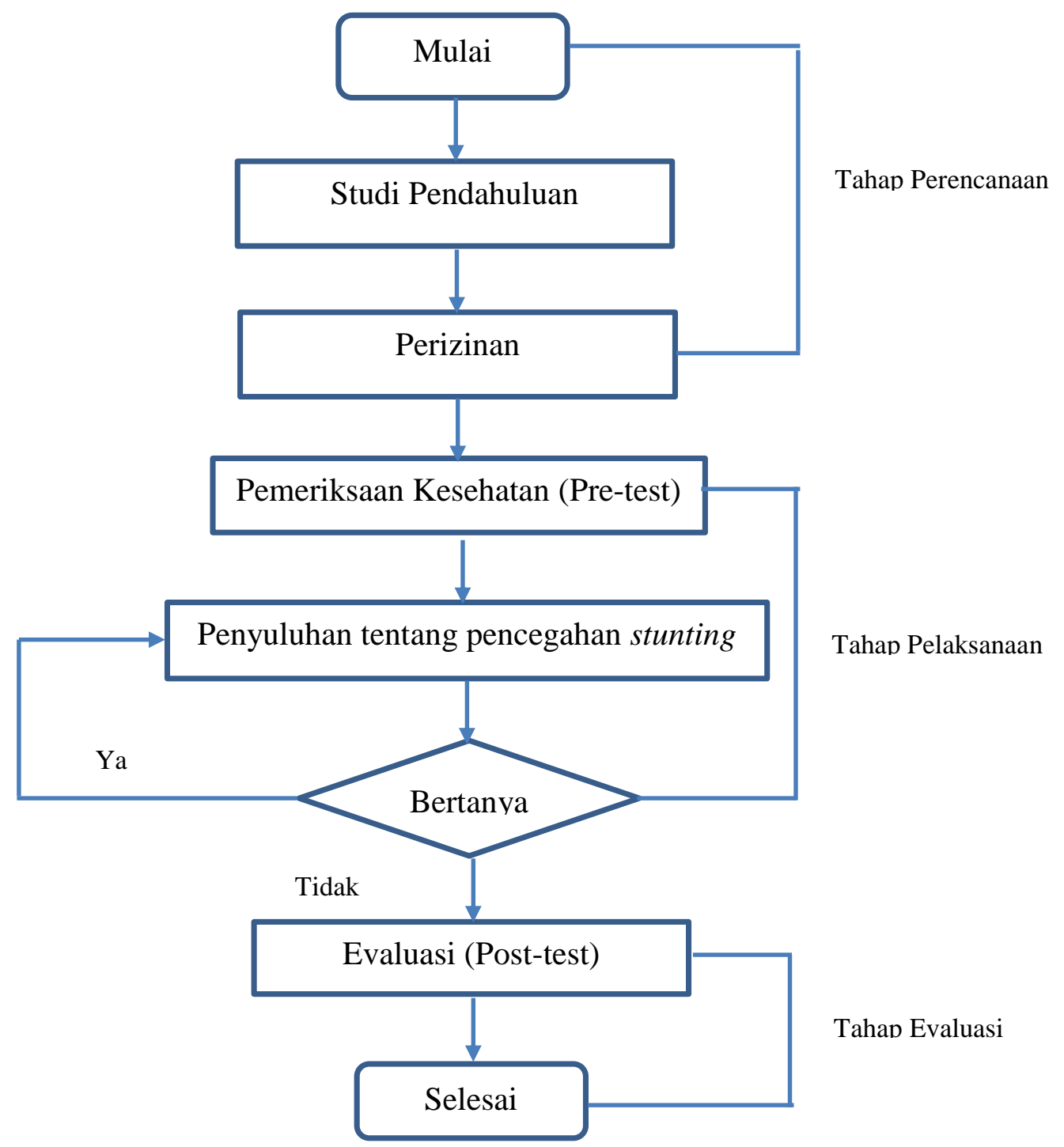

Gambar 1. Flowchat Pelaksanaan Kegiatan Pengabdian Kepada Masyarakat 
Gambar 1 dijelaskan bahwa tahap perencanaan dimulai dengan mencari informasi mengenai stunting melalui penulusuran artikel atau jurnal, penelitian yang terkait atau pengabdian masyarakat yang serupa, melakukan studi pendahuluan tentang stunting di tengah masyarakat di lokasi pengabdian. Setelah melakukan studi pendahuluan maka dilakukan perizinan kepada pihak-pihak terkait. Selanjutnya tahap pelaksanaan diawali dengan melakukan pemeriksaan kesehatan gratis untuk meningkatkan animo masyarakat terhadap kegiatan yang dilakukan dan pengisian pre-test tentang stunting dengan tujuan untuk evaluasi pengetahuan awal peserta penyuluhan. Setelah itu dilakukan penyuluhan kesehatan tentang pencegahan stunting diikuti sesi tanya jawab antara peserta dan narasumber. Penyuluhan ini dilakukan dengan metode ceramah interaktif dan tanya jawab disertai pembagian leaflet. Tahap evaluasi dilakukan dengan memberikan post-test kepada peserta dengan tujuan untuk mengetahui pengetahuan akhir peserta setelah penyuluhan,

\section{HASIL, PEMBAHASAN, DAN DAMPAK}

Berdasarkan gambar 2 menunjukkan kegiatan pengabdian diawali dengan pemeriksaan gratis untuk meningkatkan animo masyarakat tentang kegiatan pengabdian yang dilakukan dan selanjutnya dilakukan pengisian pre-test oleh peserta penyuluhan untuk mengukur pengetahuan awal peserta tentang pencegahan stunting.

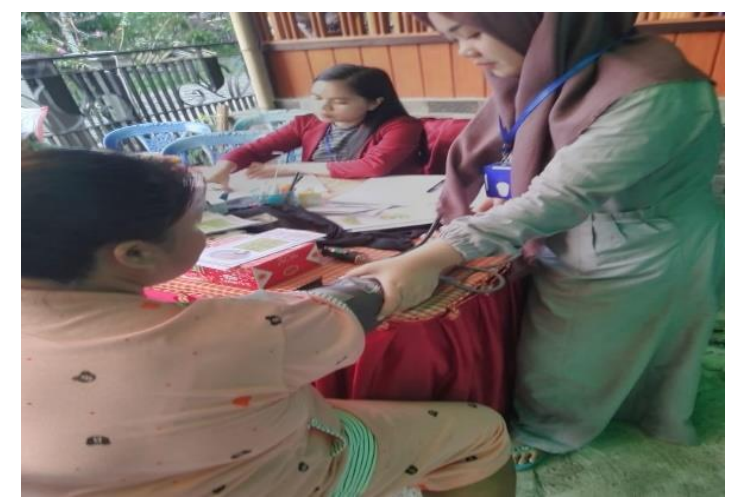

Gambar 2. Pemeriksaan kesehatan gratis

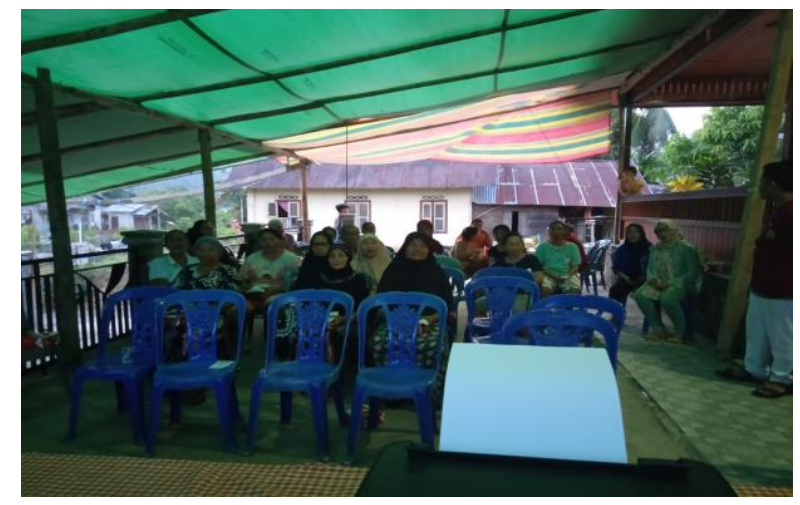

Gambar 3. Penyuluhan pencegahan stunting

Selanjutnya gambar 3 diatas menunjukkan peserta antusias mengikuti kegiatan penyuluhan tentang pencegahan stunting. Penyuluhan disampaikan dengan metode ceramah interaktif dan tanya jawab, sesi tanya jawab dimaksudkan agar masyarakat lebih aktif bertanya dan dapat menyerap materi tentang pencegahan stunting secara maksimal. Setelah penyuluhan dilakukan pengisian post-test oleh peserta untuk mengukur pengetahuan akhir peserta tentang pencegahan stunting. 
Hasil kegiatan pengabdian pada masyarakat dusun 03 Desa Muntoi Kecamatan Passi Barat Kabupaten Bolaang Mongondow dapat dilihat pada tabel 1.

Tabel 1. Perbandingan skor rata-rata pengetahuan masyarakat dusun 03 tentang stunting saat pre-test dan post-test di Desa Muntoi Kabupaten Bolaang Mongondow

\begin{tabular}{lcc}
\hline \multirow{2}{*}{ Nilai Statistik } & \multicolumn{2}{c}{ Skor Pengetahuan } \\
\cline { 2 - 3 } & Pre-test & Post-test \\
\hline Minimum & 7 & 15 \\
Maksimum & 13 & 25 \\
Mean & 10,43 & 19,60 \\
SD & 1,743 & 1,774 \\
\hline \hline
\end{tabular}

Sumber: Data Primer 2019

Tabel 1 menunjukkan bahwa rata-rata skor pengetahuan peserta penyuluhan tentang stunting pada saat pre-test adalah 10,43 dengan standar deviasi 1,743, dan pada saat posttest meningkat menjadi 19,60 dengan standar deviasi 1,774. Skor pengetahuan terendah pada saat pre-test adalah 7 dan skor tertinggi adalah 13 dan pada saat post-test skor pengetahuan terendah pada adalah 15 dan skor tertinggi adalah 25 .

Berdasarkan gambar 4 dibawah terdapat perbedaan nilai rata-rata skor pengetahuan peserta penyuluhan pada saat pre-test dan post-test dengan angka 9,17. Hal ini menunjukkan bahwa ada peningkatan pengetahuan masyarakat setelah diberikan edukasi berupa promosi kesehatan tentang pencegahan stunting.

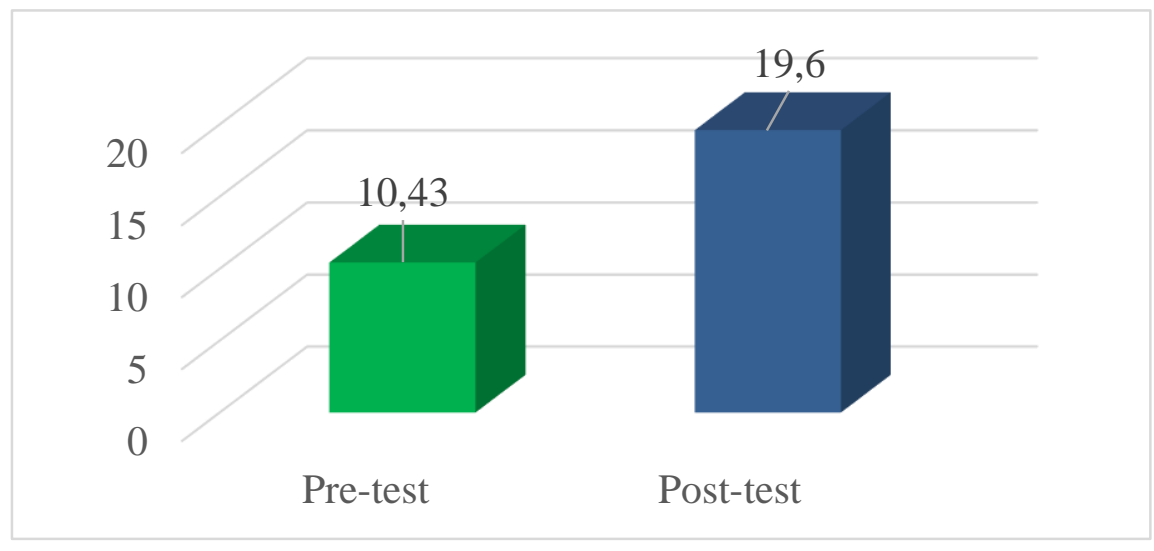

Gambar 4. Grafik skor rata-rata pengetahuan masyarakat dusun 03 tentang stunting saat pre-test dan post-test di Desa Muntoi Kabupaten Bolaang Mongondow

Hasil pengabdian masyarakat ini sejalan dengan hasil pengabdian masyarakat yang dilakukan oleh (Astuti, 2018) pada masyarakat Kecamatan Jatinagor Kabupaten Sumedang yang menyatakan bahwa gerakan pencegahan stunting melalui pelatihan meningkatkan pengetahuan kader posyandu dan melalui event HKN dapat meningkatkan pemberdayaan masyarakat dalam melakukan pencegahan stunting. Peningkatan rata-rata skor pengetahuan 
masyarakat yang cukup signifikan disebabkan oleh penerimaan materi tentang pencegahan stunting yang diberikan sangat baik.

Perilaku positif masyarakat tentang pencegahan stunting dapat timbul karena adanya kesesuaian reaksi atau respon terhadap stimulus yaitu pengetahuan tentang pencegahan stunting. Pengetahuan merupakan salah satu faktor predisposisi yang mendasari perilaku seseorang untuk berperilaku positif. Pengetahuan yang baik dapat meningkatkan perilaku masyarakat untuk melakukan pencegahan stunting secara dini (Hamzah, 2020).

Kegiatan gerakan pencegahan stunting sejalan dengan Gerakan Masyarakat Hidup Sehat (GERMAS) dari Kementrian Kesehatan dan penanganan stunting yang menjadi prioritas pemerintah diperkuat dengan telah dikeluarkannya Permendesa No. 19 Tahun 2017 tentang Prioritas Penggunaan Dana Desa, tahun 2018, penanganan stunting diprioritaskan pada 1000 desa di 100 kabupaten/kota di seluruh Indonesia, dengan penanganan melalui intervensi spesifik dan sensitif (Kemendes PDTT RI, 2018).

\section{SIMPULAN}

Kegiatan pengabdian masyarakat ini berjalan dengan baik. Serta tercapainya target yang diharapkan dengan meningkatnya pengetahuan masyarakat tentang pencegahan stunting, dimana rata-rata skor pengetahuan masyarakat saat pre-test adalah 10,43 dan dan meningkat saat post-test menjadi 19,60. Disarankan kepada masyarakat khususnya kepada ibu untuk menjaga asupan gizi selama kehamilan, saat melahirkan dan pada saat anak sebelum 2 tahun untuk mencegah terjadinya stunting. Saran untuk bidan desa dan stakeholder terkait untuk melakukan promosi kesehatan secara rutin dan berkesinambungan untuk lebih meningkatkan pengetahuan masyarakat melalui pemberdayaan masyarakat.

\section{UCAPAN TERIMAKASIH}

Terima kasih kepada pimpinan STIKES Graha Medika yang telah memberikan dukungan dalam pelaksanaan pengabdian masyarakat ini serta Kepala Desa/Sangadi Desa Muntoi Kecamatan Passi Barat Kabupaten Bolaang Mongondow Sulawesi Utara.

\section{DAFTAR PUSTAKA}

Astuti, S. (2018). Gerakan Pencegahan Stunting Melalui Pemberdayaan Masyarakat di Kecamatan Jatinangor Kabupaten Sumedang. Dharmakarya, 7(3), 185-188.

Bella, F. D., Fajar, N. A., \& Misnaniarti, M. (2020). Hubungan antara Pola Asuh Keluarga dengan Kejadian Balita Stunting pada Keluarga Miskin di Palembang. Jurnal 
Epidemiologi Kesehatan Komunitas, 5(1), 15-22.

Dinkes Sulut. (2019). Profil Kesehatan Sulawesi Utara. Dinas Kesehatan Sulut.

Hamzah, B. (2020). Menginisiasi Perilaku Positif Masyarakat Tentang Penyakit ISPA di Desa Muntoi Timur Kabupaten Bolaang Mongondow. Jurnal Pengabdian Masyarakat Al-Irsyad (JPMA), 2(1), 33-42.

Kemendes PDTT RI. (2018). Buku Saku Desa Dalam Penanganan Stunting. In Kementrian Desa PDTT.

Kemenkes RI. (2016). Situasi Balita Pendek. In Pusdatin Kemenkes RI (pp. 1-10).

Kemenkes RI. (2018). RISKESDAS. Kementrian Kesehatan RI.

Rahmayana, R. (2014). Hubungan Pola Asuh Ibu dengan Kejadian Stunting Anak Usia 2459 Bulan di Posyandu Asoka II Wilayah Pesisir Kelurahan Barombong Kecamatan Tamalate Kota Makassar Tahun 2014. Public Health Science Journal, 6(2), 424-436.

Yadika, A. D. N., Berawi, K. N., \& Nasution, S. H. (2019). Pengaruh Stunting terhadap Perkembangan Kognitif dan Prestasi Belajar. Jurnal Majority, 8(2), 273-282. 